Caldwell Patrina (Orcid ID: 0000-0003-1124-6578)

\title{
Prevalence, patient and consultation characteristics of enuresis in Australian paediatric practice.
}

Original Article

Authors: Sukanya De ${ }^{1}$

Armando Teixeira-Pinto ${ }^{2}$

Jillian R Sewell ${ }^{3}$

Patrina H Y Caldwell ${ }^{1,4}$

1 Centre for Kidney Research, The Children's Hospital at Westmead, Sydney Australia 2 Sydney School of Public Health, Sydney Medical School

3 Australian Paediatric Research Network (steering group member)

4 Discipline of Child and Adolescent Health, Sydney Medical School

Corresponding author: Sukanya De, Centre for Kidney Research, The Children's Hospital at Westmead, Locked Bag 4001, WESTMEAD NSW 2145; E mail: dr.sukanyade@gmail.com; Phone: work: 02 96356696; Mobile: 0414756598.

This is the author manuscript accepted for publication and has undergone full peer review but has not been through the copyediting, typesetting, pagination and proofreading process, which may lead to differences between this version and the Version of Record. Please cite this article as doi: 10.1111/jpc.13834

This article is protected by copyright. All rights reserved. 


\section{Figure 1. Participant recruitment}

Participant recruitment in 2008

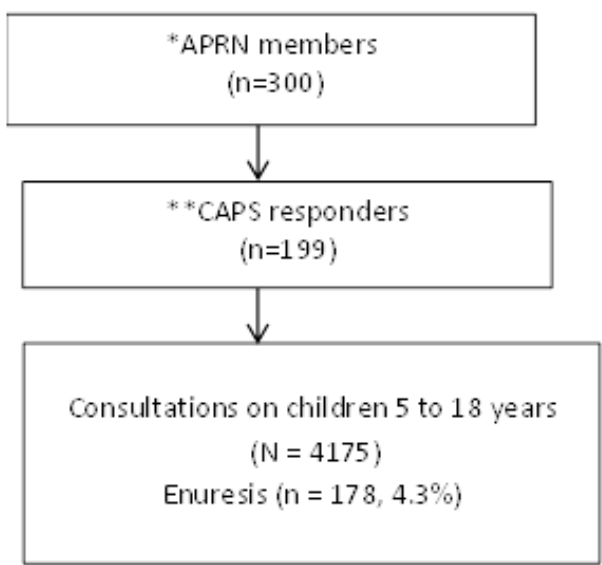

*APRN: Australian Paediatric Research Network

**CAPS: Children Attending Paediatricians Study
Participant recruitment in 2013

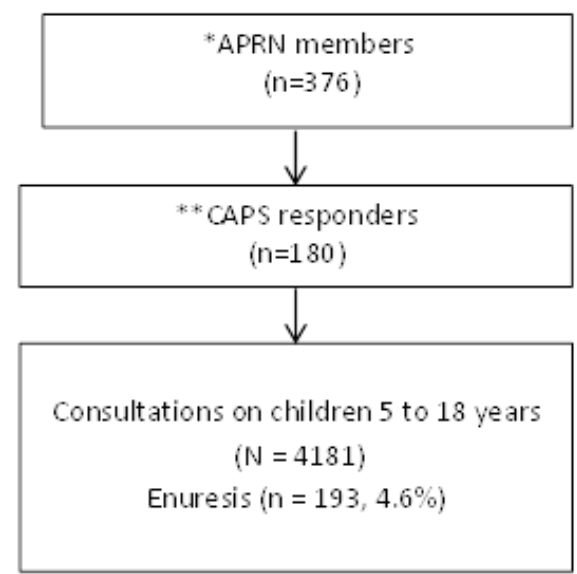

Figure 1.tif

This article is protected by copyright. All rights reserved. 


\begin{abstract}
Aims: To describe the prevalence and consultation characteristics of enuresis in Australian paediatric practice and assess for changes over a period of five years.

Methods: Data collected prospectively by paediatricians (outpatient settings) in 2008 and 2013, as part of the Children Attending Paediatricians Study (CAPS). Consultations on children aged five years or over were included. Consultations in each cohort (2008 and 2013) categorised as either listing or not listing enuresis. Characteristics of the 'enuresis' vs 'non enuresis' subgroup in each cohort were compared as were the enuresis subgroups 2008 vs 2013.
\end{abstract}

Results: Of 4175 and 4181 consultations in 2008 and 2013, enuresis was reported in 178 (4.3\%-2008) and 193 (4.6\%-2013). Constipation and encopresis were more prevalent in the enuresis vs. non enuresis subgroups [46 (25.8\%) vs. $136(3.4 \%)$ for constipation and 25 $(14 \%)$ vs. $65(1.6 \%)$ for encopresis in 2008; 52 (26.9\%) vs. 160 (4\%) for constipation and 25 $(13 \%)$ vs.78 (2\%) for encopresis in 2013, both $\mathrm{p}<0.001]$. The enuresis subgroup had more referrals to multidisciplinary teams $[19(10.7 \%)$ vs 148 (3.7\%) - 2008 and $21(10.9) \%$ vs 163 $(4.1 \%)$ - 2013, both $\mathrm{p}<0.001]$ and allied health professionals [29 (16.3\%) vs $230(5.8 \%)$ 2008; 27 (14\%) vs 178 (4.5\%) - 2013, both $\mathrm{p}<0.001]$.

Conclusion: The overall frequency of presentation of children for management of enuresis was low. Prevalence/consultation characteristics of enuresis were comparable over 5 years. Constipation and encopresis were significantly more prevalent in the enuresis subgroups.

This article is protected by copyright. All rights reserved. 


\section{Key Words:}

Enuresis; Prevalence; Paediatrics

\section{What is already known:}

- Enuresis is common in children, affecting almost a fifth of Australians aged between five and twelve years.

- It affects self-esteem and quality of life as well as causing parental stress.

\section{What this study adds:}

- We found the prevalence of enuresis in Australian paediatric practice to be quite low highlighting that there is a need to explore the health seeking behaviours of parents and referral practices of primary care practitioners who assess these children.

- Up to a quarter of children with enuresis also had constipation and faecal incontinence affected up to fourteen percent, highlighting the need to screen for bowel problems in all children with enuresis.

This article is protected by copyright. All rights reserved. 


\section{Introduction}

Enuresis is a common paediatric problem affecting up to of $19 \%$ Australian children aged between 5 and 12 years. ${ }^{1}$ It has a negative impact on health, self-esteem and quality of life of affected children and causes considerable parental stress. ${ }^{2,3}$ Treating enuresis results in improved quality of life of affected children and their families. ${ }^{4}$ However according to one Australian survey parents of only a third of children with enuresis ever consult a health care worker let alone a paediatrician. ${ }^{1}$ Knowledge of the case load and consultation characteristics of children with enuresis is important for appropriate clinical service provision, in terms of ensuring service availability, appropriate resource allocation and training of paediatric clinical and allied health professionals in the management of enuresis. The prevalence of enuresis in Australian paediatric practice is not known. Hence the primary aim of this study is to describe the prevalence of enuresis in paediatric practice along with patient and consultation characteristics. Our secondary aim is to determine if there has been a change in prevalence or consultation characteristics of enuresis over a five year interval.

\section{Methods}

We reviewed data collected prospectively during two nationwide paediatric audits held in 2008 and 2013, as part of the Children Attending Paediatricians Study (CAPS) conducted by the Australian Paediatric Research Network (APRN). The APRN is a national research network that aims to facilitate multi-site research in pediatric outpatient settings. ${ }^{5}$ The initial CAPS study, consisted of a 2 week nationwide survey of general and developmental/community paediatricians (October-November 2008) and is detailed elsewhere. ${ }^{6}$ All members of the APRN who self-nominated as general, community or developmental pediatricians were invited to participate in the Children Attending Pediatricians Study. Subspecialists and paediatricians with no outpatient practice were excluded. A second nationwide survey was similarly conducted in November-December 2013. The diagnosis of enuresis has an age criteria of five years or above, hence for this study only the consultations on children who were 5years of age or older were included.

Data collection: A data collection form was developed, piloted and finalised as has been detailed elsewhere. ${ }^{6}$ Paediatricians were mailed a booklet of forms to complete for the first 100 consecutive presentations or for two weeks, whichever came first. Paediatricians 
prospectively recorded de-identified information for every patient seen in secondary care (outpatient) setting. The questionnaire had the provision for paediatricians to record up to four diagnoses/clinical problems in the 2008 survey and up to five diagnoses/clinical problems in the 2013 survey for each consultation, from a list of 60 pre-coded conditions. Paediatricians' practice location was determined from the APRN members' database. The completed forms were scanned using Cardiff Teleform 10.0 software (Cardiff, Vista, Calif, USA). One member (JRS) coded the additional hand written diagnoses. Pediatricians sought parents' verbal consent to record information. Institutional ethics approval was obtained from the Royal Children's Hospital, Melbourne Human Research Ethics Committee.

Statistical analysis: For the purpose of this study we grouped consultations into three age categories: children aged five to seven years, eight to twelve years and thirteen years or older. For each cohort (2008 and 2013), we grouped consultations into two categories-those that included enuresis in the diagnoses listed by the reporting paediatricians and those that did not. We described and compared consultation characteristics of the enuresis and non enuresis subgroups in each cohort (2008 and 2013) including age category, gender, practice setting (rural versus metropolitan), body mass index (BMI), referral to multidisciplinary teams, sub specialists or allied health professionals and parental rating of their child's health. The ten most common diagnoses (comorbidities) listed in the enuresis and non enuresis subgroups for each study cohort were identified. We also compared the enuresis sub groups for the two cohorts (2008 and 2013) to assess for any changes in consultation characteristic over five years. Statistical significance for difference between proportions was calculated using Chi square test or Fisher exact test (if frequencies were low).

\section{Results}

There were 199 and 180 participating paediatricians in the 2008 and 2013 surveys respectively. They provided data on 4175 and 4181 consultations (involving children five years or older) in 2008 and 2013 respectively. In Figure 1 we have details the participant recruitment for the APRN surveys 2008 and 2013.

Consultation characteristics (Table 1): Enuresis was reported in 178 of 4175 consultations (4.3\%) in 2008 and in 193 (4.6\%) of 4181 consultations in 2013. A significantly higher proportion of consultations were in the 5 to 7 and 8 to 12 year age categories for the enuresis subgroups. A significantly smaller proportion of consultations involving enuresis took place 
in rural/regional settings. Overall parental rating of their child's health did not differ between the enuresis and non enuresis sub groups. Body Mass Index (BMI) was not notably different in the enuresis vs. non enuresis sub groups. A significantly greater proportion of children in the enuresis sub groups were referred to a multidisciplinary team and/or allied health professionals.

Most common diagnoses listed in the enuresis vs. non enuresis subgroups: Constipation and encopresis were the most commonly reported conditions in the enuresis subgroups in both study cohorts while attention deficit hyperactivity disorder was the most common diagnosis in the non enuresis sub groups followed by autism spectrum disorder and learning difficulties. Constipation was reported in over a quarter of consultations in the enuresis subgroups, both 2008 and 2013. Encopresis (faecal incontinence) was reported in 25 (14\%) of 178 consultations in the 2008 and 25 (13\%) of 193 consultations in the 2013 enuresis subgroups. In comparison constipation was reported in only $136(3.4 \%)$ of 3997 and 160 (4\%) of 3988 consultations in the non enuresis subgroups in 2008 and 2013 respectively. Encopresis was reported in $65(1.6 \%)$ of 3997 and $78(2 \%)$ of 3988 consultations in the non enuresis subgroups in 2008 and 2013 respectively.

\section{Discussion}

In this nationwide survey of participating paediatricians we found the prevalence of enuresis in paediatric practice to be quite small. The prevalence and consultation characteristics of enuresis in 2008 and 2013 were similar. A significantly larger proportion of the children with enuresis had constipation and faecal incontinence as compared to children without enuresis. Consultations that had enuresis listed among the diagnoses had a higher number of referrals to multidisciplinary teams and allied health professionals than the consultations where enuresis was not reported.

The relatively low prevalence of enuresis in paediatric practice is in contrast to the relatively high prevalence of enuresis among children in the community. While it is possible that some children with enuresis are assessed and managed effectively by their general practitioners or a continence nurse thus effectively reducing the number of presentations to secondary care settings, to our knowledge there is no data on prevalence or current management practices for 
enuresis at primary care level. Given the paucity of data in this context, other equally plausible reasons for the relatively infrequent presentation of enuresis cases to paediatricians could be parental attitudes or lack of parental/general practitioners' awareness of treatment options. There is some data to suggest that enuresis may be under reported by parents. Our finding of low prevalence of enuresis in paediatric practice is in keeping with the findings of a survey of parents of children aged 5-12 years that reported that only about a third of children with enuresis saw a health care worker. ${ }^{1}$ According to one American survey only $28 \%$ of parents reported awareness of effective medical treatments for enuresis and $55 \%$ reported that they would seek medical care for a child with enuresis. ${ }^{7}$ According to one qualitative study parents of children with enuresis may feel reluctant to bring up the subject of bed wetting during consultations and would rather have the health care provider raise the issue during routine check-up time. ${ }^{2}$ While primary care physicians should and perhaps to an extent do manage enuresis thus appropriately offsetting the need for these children to present to secondary/tertiary care we do not have data to confirm this. In our clinical experience, parents presenting to paediatricians often report that they believed or were advised by their treating family physician that their child would eventually outgrow bedwetting suggesting lack of awareness in the community and even among some health professionals regarding suitable treatment options. More studies are needed to assess the screening, management and referral practices in relation to enuresis at primary care level.

The prevalence of constipation and faecal incontinence was significantly higher in the enuresis versus non enuresis groups. Our finding of a high prevalence of constipation in association with enuresis has been previously reported. ${ }^{8-10}$ Our findings highlight the interrelationship between bladder and bowel dysfunction and reinforce the importance of screening all children with enuresis for underlying bowel problems. While we could not verify reasons for referral to multidisciplinary teams /allied health professionals, it is possible that some children with enuresis, especially those not responding to standard therapy and those with behavioural/psychosocial comorbidities, need multidisciplinary assessment and support.

We did not find a higher prevalence of ADHD, anxiety, behavioural problems or obesity among the enuresis groups although these conditions are known to coexist with enuresis. ${ }^{11-14}$. 
However these disorders are more likely to be present in a smaller, more complex subset of children with enuresis, ${ }^{14-16}$ and the number of children with enuresis in our study population was possibly too small to accurately identify any increase in occurrence of disorders in this subset. It is also possible that enuresis, while discussed and even managed during consultations for some children with complex neurodevelopmental disorders and multiple challenging issues, was not reported in some instances by the treating paediatrician owing to the multiplicity of diagnoses. Our finding of a significantly lower proportion of children with enuresis presenting to rural regional practice perhaps reflects longer waiting times to be seen by a paediatrician in these areas resulting in management by general practitioners and referral to metropolitan services.

To our knowledge no previous study has assessed the prevalence of enuresis in Australian paediatric practice. Ours findings are based on two nationwide surveys with robust sample size. By way of limitations, our study did not record the prevalence of day time urinary symptoms which may coexist with enuresis. Reasons for referral to multidisciplinary teams or allied health professionals could not be ascertained. In the APRN survey paediatricians had the scope to record a maximum of four diagnoses (in 2008) and (five diagnoses) in 2013 per consultation. Thus in children with complex, multiple problems enuresis may have not been reported (although managed) by the treating paediatrician as several other diagnoses may have taken precedence. This reporting bias may have falsely lowered our estimate of enuresis cases seen in paediatric practice. However, the proportion of such cases where enuresis may have been addressed during the consultation but not reported is likely to be small since paediatricians listed the maximum feasible number of diagnoses in $422(10 \%)$ consultations in the 2008 survey and in just 83 (2\%) consultations in the 2013 survey.

\section{Conclusion}

The overall prevalence and consultation characteristics of enuresis remain largely unchanged over a five year period. Children presenting with enuresis should be routinely screened for comorbid constipation and faecal incontinence. Our finding of relatively low prevalence of enuresis in paediatric practice highlights the need to study the prevalence of enuresis in primary care and the management practices of primary health care professionals including 
general practitioners and continence nurses as well as exploring the health seeking behaviours of parents of children with enuresis including potential barriers to presentation for medical management.

This article is protected by copyright. All rights reserved. 


\section{References}

1. Bower WF, Moore KH, Shepherd RB, Adams RD. The epidemiology of childhood enuresis in Australia. Br J Urol. 1996;78(4):602-6.

2. Cederblad M, Neveus T, Ahman A, Osterlund Efraimsson E, Sarkadi A. "Nobody asked us if we needed help": Swedish parents experiences of enuresis. J Pediatr Urol. 2014;10(1):74-9.

3. Kanaheswari Y, Poulsaeman V, Chandran V. Self-esteem in 6- to 16-year-olds with monosymptomatic nocturnal enuresis. J Paediatr Child Health. 2012;48(10):E178-82.

4. Naitoh Y, Kawauchi A, Soh J, Kamoi K, Miki T. Health related quality of life for monosymptomatic enuretic children and their mothers. J Urol. 2012;188(5):1910-4.

5. Hiscock H, Efron D, Wasserman R, Wake M. Power to the paediatricians: The Australian Paediatric Research Network is born. J Paediatr Child Health. 2012;48(1):6-9.

6. Hiscock H, Roberts G, Efron D, Sewell JR, Bryson HE, Price AMH, et al. Children Attending Paediatricians Study: a national prospective audit of outpatient practice from the Australian Paediatric Research Network. Med J Aust. 2011;194:392-7.

7. Schlomer B, Rodriguez E, Weiss D, Copp H. Parental beliefs about nocturnal enuresis causes, treatments, and the need to seek professional medical care. J Pediatr Urol.9(6 Pt B):1043-8.

8. Dehghani SM, Basiratnia M, Matin M, Hamidpour L, Haghighat M, Imanieh MH. Urinary tract infection and enuresis in children with chronic functional constipation. Iran J Kidney Dis.7(5):363-6.

9. Hodges SJ, Anthony EY. Occult megarectum--a commonly unrecognized cause of enuresis. Urology.79(2):421-4.

10. McGrath KH, Caldwell PH, Jones MP. The frequency of constipation in children with nocturnal enuresis: a comparison with parental reporting. J Paediatr Child Health.44(1-2):19-27.

11. Shreeram S, He JP, Kalaydjian A, Brothers S, Merikangas KR. Prevalence of enuresis and its association with attention-deficit/hyperactivity disorder among U.S. children: results from a nationally representative study. J Am Acad Child Adolesc Psychiatry. 2009;48(1):35-41.

12. Erdem E, Lin A, Kogan BA, Feustel PJ. Association of elimination dysfunction and body mass index. J Pediatr Urol.2(4):364-7.

13. Fergusson DM, Horwood LJ. Nocturnal Enuresis and Behavioral Problems in Adolescence: A 15-Year Longitudinal Study. Pediatrics. 1994;94(5):662-8.

14. Joinson C, Heron J, Emond A, Butler R. Psychological Problems in Children with Bedwetting and Combined (day and night) Wetting: A UK Population-Based Study. J Pediatr Psychol. 2007;32(5):605-16.

15. Baeyens D, Roeyers H, D'Haese L, Pieters F, Hoebeke P, Vande Walle J. The prevalence of ADHD in children with enuresis: comparison between a tertiary and non-tertiary care sample. Acta Paediatr.95(3):347-52.

16. von Gontard A, Moritz AM, Thome-Granz S, Freitag C. Association of attention deficit and elimination disorders at school entry: a population based study. J Urol.186(5):2027-32.

This article is protected by copyright. All rights reserved. 
Table 1 Consultation characteristics in 2008 and 2013

\begin{tabular}{|c|c|c|c|c|c|c|}
\hline \multirow[b]{3}{*}{ Consultations characteristic } & \multicolumn{3}{|c|}{ Consultations in 2008} & \multicolumn{3}{|c|}{ Consultations in 2013} \\
\hline & \multicolumn{3}{|c|}{$[N=4175]$} & \multicolumn{3}{|c|}{$[N=4181]$} \\
\hline & Enuresis & Non enuresis & p value & Enuresis & Non enuresis & p value \\
\hline & $\mathrm{n}=178$ & $\mathbf{n}=\mathbf{3 9 9 7}$ & & $n=193$ & $\mathrm{n}=\mathbf{3 9 8 8}$ & \\
\hline & $(4.3 \%)$ & $(95.7 \%)$ & & $(4.6 \%)$ & $(95.4 \%)$ & \\
\hline \multicolumn{7}{|l|}{ Age group } \\
\hline $5-7$ years $(\%)$ & $71(39.9)$ & $1143(28.6)$ & & $71(36.8)$ & $1133(28.4)$ & \\
\hline $8-12$ years $(\%)$ & $83(46.6)$ & $1729(43.3)$ & $<0.001$ & $93(48.2)$ & $1679(42.1)$ & $<0.001$ \\
\hline e 13 years $(\%)$ & $24(13.5)$ & $1125(28.1)$ & $?$ & $29(15.0)$ & $1176(29.5)$ & \\
\hline Female gender & $77(46.1)$ & $1297(34.6)$ & 0.003 & $68(37.8)$ & $1322(36.0)$ & 0.690 \\
\hline $\mathbf{A T S I}^{\dagger}$ & $5(2.5)$ & $175(3.6)$ & 0.492 & $0(0.0)$ & $108(2.2)$ & 0.055 \\
\hline Rural consultation location & $32(18.1)$ & $1069(27.8)$ & 0.006 & $16(8.6)$ & $922(24.0)$ & $<0.001$ \\
\hline Parents' rating of child's hea & & & & & & \\
\hline
\end{tabular}




\begin{tabular}{|c|c|c|c|c|c|c|}
\hline Poor $(\%)$ & $1(0.7)$ & $129(3.9)$ & & $1(0.8)$ & $114(3.4)$ & \\
\hline Fair $/ \operatorname{good}(\%)$ & $70(46.3)$ & $1708(51.2)$ & 0.034 & $52(44.1)$ & $1784(52.5)$ & 0.034 \\
\hline Very good/excellent (\%) & $80(53.0)$ & $1497(44.9)$ & & $65(55.1)$ & $1502(44.2)$ & \\
\hline \multicolumn{7}{|l|}{ Body Mass Index (BMI) } \\
\hline BMI $>85^{\text {th }}$ centile $(\%)$ & $40(28.4)$ & $661(26.1)$ & 0.628 & $33(26.6)$ & $724(26.3)$ & $>0.999$ \\
\hline BMI $>95^{\text {th }}$ centile $(\%)$ & $20(14.2)$ & $328(13.0)$ & 0.774 & $13(10.5)$ & $366(13.3)$ & 0.439 \\
\hline \multicolumn{7}{|l|}{ Referral to another service } \\
\hline A multidisciplinary team & $19(10.7)$ & $148(3.7)$ & $<0.001$ & $21(10.9)$ & $163(4.1)$ & $<0.001$ \\
\hline Psychologist & $18(10.1)$ & $460(11.5)$ & 0.651 & $17(8.8)$ & $546(13.7)$ & 0.067 \\
\hline Other allied health professional ${ }^{\ddagger}$ & $29(16.3)$ & $230(5.8)$ & $<0.001$ & $27(14.0)$ & $178(4.5)$ & $<0.001$ \\
\hline Constipation $^{\S}$ & $46(25.8)$ & $136(3.4)$ & $<0.001$ & $52(26.9)$ & $160(4.0)$ & $<0.001$ \\
\hline Encopresis $^{\S}$ & $25(14.0)$ & $65(1.6)$ & $<0.001$ & $25(13.0)$ & $78(2.0)$ & $<0.001$ \\
\hline
\end{tabular}

${ }^{\dagger}$ Aboriginal or Torres Strait Islander; ${ }^{\ddagger}$ Psychologist, speech pathologist, audiologist excluded; ${ }^{\S}$ Constipation and encopresis not mutually exclusive 
Table 2: Ten most common diagnoses reported in the enuresis and non enuresis subgroups

\begin{tabular}{|c|c|c|c|}
\hline Consultations in 2008 & & Consultations in 2013 & \\
\hline Enuresis subgroup & Non enuresis subgroup & Enuresis subgroup & Non enuresis subgroup \\
\hline$n=178$ & $n=3997$ & $n=193$ & $\mathrm{n}=3988$ \\
\hline Constipation, 46 (25.8\%) & ADHD/ADD, 1363 (30.8) & Constipation, 52 (26.9\%) & ADHD/ADD, 1448 (33.5\%) \\
\hline Encopresis, 25 (14.0\%) & Learning difficulty, 550 (12.4\%) & Encopresis, 25 (13\%) & ASD, 799 (18.5\%) \\
\hline Learning difficulty, 22 (12.4\%) & ASD, $414(9.4 \%)$ & Sleep disturbance, 22 (11.4\%) & Learning difficulty, 560 (12.9\%) \\
\hline ADHD/ADD, 20 (11.2\%) & Behaviour, 329 (7.4\%) & ASD, $20(10.3 \%)$ & Anxiety, 442 (10.2\%) \\
\hline Overweight/Obesity, 11 (6.2\%) & Intellectual disability, 296 (6.7\%) & ADHD/ADD, 19 (9.8\%) & Intellectual disability, 335 (7.7\%) \\
\hline Behaviour, 9 (5.0\%) & Anxiety, 292 (6.6\%) & Anxiety, 15 (7.8\%) & Behaviour, 334 (7.7\%) \\
\hline ASD, $8(4.5 \%)$ & Asthma, 245 (5.5\%) & Behaviour, 13 (6.7\%) & Sleep disturbance, 272 (6.3\%) \\
\hline ODD, $8(4.5 \%)$ & ODD, 244 (5.5\%) & Learning difficulty, 12 (6.2\%) & ODD, 267 (6.2\%) \\
\hline Anxiety, 8 (4.5\%) & Overweight/Obesity, 183 (4.1\%) & Overweight/Obesity, 10 (5.2\%) & Asthma, 258 (6.0\%) \\
\hline Urinary tract infection, 5 (2.8\%) & Seizures - generalized, 161 (3.6\%) & Renal tract, $8(4.1 \%)$ & Overweight/Obesity, 203 (5.0\%) \\
\hline
\end{tabular}

AHDH/ADD Attention Deficit Hyperactivity Disorder / Attention Deficit Disorder; ASD Autism Spectrum Disorder; ODD Oppositional Defiant Disorder

This article is protected by copyright. All rights reserved. 
Figure 1. Participant recruitment

This article is protected by copyright. All rights reserved. 


\section{University Library}

\section{- M M N E R VA A gateway to Melbourne's research publications}

Minerva Access is the Institutional Repository of The University of Melbourne

Author/s:

De, S;Teixeira-Pinto, A;Sewell, JR;Caldwell, PHY

Title:

Prevalence, patient and consultation characteristics of enuresis in Australian paediatric practice

Date:

2018-06-01

Citation:

De, S., Teixeira-Pinto, A., Sewell, J. R. \& Caldwell, P. H. Y. (2018). Prevalence, patient and consultation characteristics of enuresis in Australian paediatric practice. JOURNAL OF PAEDIATRICS AND CHILD HEALTH, 54 (6), pp.620-624. https://doi.org/10.1111/jpc.13834.

Persistent Link:

http://hdl.handle.net/11343/283481 